\title{
Pylorectomy and Gastroduodenostomy (Billroth I Procedure) for Obstructive Antrum Pyloric Leiomyoma in a Bitch
}

\author{
Idalini Cima', Alex dos Santos', Claudia Cerutti Dazzi', Tanise Policarpo Machado², \\ Adriana Costa da Motta ${ }^{2}$, Josiane Borges ${ }^{3}$, Rubens Rodriguez ${ }^{3}$ \& Marco Augusto Machado Silva ${ }^{4}$
}

\begin{abstract}
Background: Gastric neoplasms are uncommon in dogs, especially those affecting smooth muscle layers. Leiomyoma is a smooth muscle benign neoplasm, which requires surgical resection. Pylorectomy and gastroduodenostomy (Billroth I procedure) is the most indicated technique in cases not affecting the biliary and pancreatic tracts. Thus, the purpose of this study was to report a successful case of Billroth I procedure in a bitch presenting antrum pyloric obstructive leiomyoma. Case: A 12-year-old, non-spayed, Cocker Spaniel bitch was admitted presenting depression, hyporexia, postprandial vomiting and sparse episodes of hematemesis, for 30 days. Clinical suspicion on obstructive gastric outflow disease was established. Bloodwork (complete blood count, BUN, albumin, ALP and ALT), abdominal ultrasound and thoracic radiographs were assessed. The patient undergone upper gastrointestinal endoscopy. On endoscopic evaluation, small hemorrhagic mucosa ulcers were visualized on the gastric body, antrum and pylorus. Moreover, a sessile, ulcerated, round-shape and infiltrated antral-pyloric mass was seen. The mass was $1.5-2.0 \mathrm{~cm}$ in diameter and apparently involved the smooth muscle layer, causing severe pyloric obstruction. However, endoscopic evaluation of the duodenum was possible. Several biopsy samples were taken from the neoplasm and sent for histopathologic assessment. The result was not conclusive due to low quality samples. The patient had progressive worsening of obstruction episodes and required surgery. A wide-margin pylorectomy and gastroduodenostomy (Billroth I procedure) was carried out. The retrieved specimen was sent to histopathological and immunohistochemistry (IHC) assessment. Positive staining for actin and desmin confirmed smooth muscle origin of the mass and histopathological assessment confirmed leiomyoma. The patient underwent regular periodic postoperative assessments, revealing progressive clinical improvement and normal weight gain. Control upper gastrointestinal endoscopy was performed. Gastric ulcers were completely healed and gastroduodenal anastomosis was functional. The anastomotic scar tissue was sampled and revealed chronic and normal healing process. Complete healing was confirmed and the patient was discharged.

Discussion: Gastric neoplasms are not common in dogs. However, severe obstruction of gastric outflow is a potential risk for complications in those cases. Upper gastrointestinal endoscopic assessment is important not only for diagnosis, but also for surgery decision making. In the current study, gastroscopy provided accurate preoperative evaluation of severity of pyloric obstruction and diagnosis of secondary gastric ulcers. Direct visualization of lesions and multiple biopsy sampling were performed. The presence of neoplasms over $2-\mathrm{cm}$ in diameter indicates need for complete laparoscopic or conventional surgical resection. In this case report, open resection was carried out due to prohibitive cost of laparoscopic approach, mass dimensions and probable involvement of deeper tissue layers. In conclusion, pylorectomy and gastroduodenostomy (Billroth I procedure) was curative and provided good prognosis following resection of an antrum pyloric obstructive leiomyoma. Endoscopy was critical for both diagnosis and decision-making towards surgery for gastric outflow obstruction due to an antrum pyloric neoplasm. Histopathological and immunohistochemistry assessment confirmed neoplasm type and assured oncological safety of resection with wide margins.
\end{abstract}

Keywords: gastric neoplasms, smooth muscle tumor, endoscopy, dog. 


\section{INTRODUCTION}

Gastric neoplasms are relatively uncommon in companion animals. Adenocarcinoma is the most frequent gastric tumor (42-72\% of all gastric neoplasms) in dogs $[3,16]$. Smooth muscle tumors present lower occurrence. Leiomyoma can affect any segment of the gastrointestinal tract. However, gastroesophagic junction is the most common affected area. Obstructive syndrome is the main complication in those cases [3].

Differential diagnosis of gastric neoplasms include congenital or acquired antrum pyloric hyperplasia, fungal granulomatous disease, eosinophilic granulomas and pyloric foreign bodies [16]. Gastric tumors are usually asymptomatic until severe obstructive disease develops [21].

Surgical treatment of gastric neoplasms is challenging and prognosis depends on malignancy, age, gastric area, involvement of biliary and/or pancreatic tracts, as well as proper surgical technique [6,19]. Several techniques were reported for treating gastric cancer. Billroth I procedure (pylorectomy/gastroduodenostomy) is the surgery of choice if biliary and pancreatic tracts are not severely compromised [6,20].

Even though great progress was achieved towards diagnosis and treatment of gastric neoplasms, prognosis data are still conflicting. Thus, the purpose of this study was to report a successful case of Billroth I procedure for treating pyloric leiomyoma in a bitch presenting chronic gastric outflow obstruction.

\section{CASE}

A 12-year old, non-spayed, Cocker Spaniel bitch, weighing $9 \mathrm{~kg}$, was admitted presenting depression, hyporexia, intermittent vomiting following food intake and mild hematemesis for 30 days. On physical examination, superficial mucosa were pale and abdominal palpation revealed mild pain on the epigastric area. A suspicion on gastric emptying due to hypertrophic pyloric disease or neoplasm was established.

Basic bloodwork (CBC, BUN, albumin, ALP, ALT), abdominal echography and thoracic radiography were assessed. Mild leukocytosis with regenerative left shift and macrocytic normochromic anemia, as well as moderate raise on BUN and mild decrease on serum albumin were the main hematological findings. Thoracic radiographs were normal. Abdominal echography revealed gastric dilatation with gas, fluid and food. A heterogenic, non-pedunculated and spherical mass of approximately $1.5-2.0 \mathrm{~cm}$ diameter was found at the pylorus.
The patient undergone gastroduodenoscopy to confirm pyloric neoplasm. Mild amount of small ulcers were viewed along the antrum pyloric mucosa. The mass, a sessile, ulcerated, infiltrative, round-shaped tumor, was present at the pyloric area (Figure $1 \mathrm{~A} \&$ B). The tumor presented approximately $1.5-2.0 \mathrm{~cm}$ in diameter and caused severe obstruction of the pyloric sphincter. Although it was difficult to pass the endoscope through the pylorus, duodenoscopy was possible. Duodenal mucosa was mildly edematous. Proximal and distal duodenal papillae were preserved. Biopsy samples were taken from the mass, antrum pyloric and duodenum using a $2.3 \mathrm{~mm}$ cup-type forceps. Multiple samples (10) were taken from the same point of the mass in order to obtain deeper tissue. The mass apparently affected the smooth muscle layer, as the mucosa slipped over it during biopsy sampling.

Specimen were stored in $10 \%$ buffered formalin solution and sent for histopathological assessment using optic microscopy. Standard hematoxylin and eo$\sin (\mathrm{H} \& \mathrm{E})^{1}$ staining was performed. Gastric and duodenal mucosa biopsies revealed mild lymphoplasmacytic gastroduodenitis, based on the criteria established by the WSAVA [5]. Biopsies taken from the mass were inconclusive due to poor quality samples.

The patient undergone surgical resection of the pylorus, with $3 \mathrm{~cm}$ margins, followed by gastroduodenostomy (Billroth I procedure). The gastroduodenal anastomosis was carried out using 2-0 USP polyglecaprone 25 (Caprofyl $\left.^{\mathrm{TM}}\right)^{2}$ thread, in a simple continuous pattern. The abdomen was closed routinely. The patient remained hospitalized receiving RLS (Solução de Ringer com Lactato $)^{3}$ fluid therapy $\left(50 \mathrm{~mL} \cdot \mathrm{kg}^{-1}\right.$, for $24 \mathrm{~h}$ ), omeprazol (Oprazon ${ }^{\mathrm{TM}^{4}}, 1 \mathrm{mg} \cdot \mathrm{kg}^{-1}$, SID, IV), enrofloxacin (Chemitril ${ }^{\mathrm{TM}} 2,5 \%$, 5 mg. $\mathrm{kg}^{-1}$, BID, IV, for 5 days), metronidazol (Endonidazol ${ }^{\mathrm{TM}} 6,15 \mathrm{mg} \cdot \mathrm{kg}^{-1}$, BID, IV, for $24 \mathrm{~h})$, ondasentron chloride $\left(0,22 \mathrm{mg} . \mathrm{kg}^{-1}\right.$, TID, IV, for 3 days), dipyrone-scopolamine association (Buscopan composto ${ }^{\mathrm{TM} 8}, 25 \mathrm{mg} \cdot \mathrm{kg}^{-1}$, TID, IV, for 3 days), sucralfate (Sucrafilm ${ }^{\mathrm{TM} 9}, 20 \mathrm{mg} \cdot \mathrm{kg}^{-1}$, TID, VO, for 3 days) and tramadol chloride ${ }^{10}\left(3 \mathrm{mg} \cdot \mathrm{kg}^{-1}\right.$, TID, IV, for 3 days). Small amount of liquid commercial dog food and water was offered $16 \mathrm{~h}$ after surgery. Consistency and amount of food was progressively increased. Normal commercial dry food diet started by the fourth day postoperatively (PO). Hospital discharge occurred at the sixth day PO.

Resected specimen was stored in $10 \%$ buffered formalin solution. On gross examination, the resected 
piece presented $4.5 \times 4.0 \times 2.5 \mathrm{~cm}$ margins (length, height and depth). After tissue section, a $1.7 \mathrm{~cm}$ encapsulated, white-pale brown colored and soft-firm mass was found partially obstructing the pylorus. The mass did not infiltrate the gastric mucosa. Microscopic evaluation following $\mathrm{H} \& \mathrm{E}$ staining revealed proliferation of mature smooth muscle cells. Those cells were well delimited and arranged in solid pattern (Figure 2B). There were rare mitosis and moderate cell shape variations. Additionally, immunohistochemical assay (IHC) was performed using the polymer method with horseradish peroxidase (HiDef Detection ${ }^{\mathrm{TM}}$ HRP Polymer System $)^{11}$, with positive control. The following monoclonal antibodies and dilutions were used: actin (HHF35 Thermo Scientific $\left.{ }^{\text {TM }}{ }^{12}, 1: 300\right)$, desmin (D33 Cell Marque ${ }^{\text {TM11 }}$, 1:100), CD34 (QBEnd/10 Cell Marque $^{\text {TM11 }}$, 1:100), DOG-1 (SP31 Cell Marque ${ }^{\text {TM11, }}$ 1:100), CD117 (YR145 Cell Marque $\left.{ }^{\mathrm{TM} 11}, 1: 100\right)$. Phosphate buffered solution (PBS) was used for dilutions. There was positive immune reaction for actin (Figure
2C) and desmin (Figure 2D), confirming smooth muscle origin. Thus, the diagnosis of leiomyoma was set.

The patient was followed up in 15-day intervals for assessment of possible local tumor recurrence or evidence of late PO complications for four months. Additional bloodwork and abdominal echography were performed. Macrocytic normochromic anemia lasted for 30 days PO, which resolved without clinical management. The patient remained clinically healthy and presented normal progressive weight gain.

At the fourth month PO, the patient undergone new gastrointestinal endoscopy for routine control. The gastric ulcers healed completely. The anastomosis was completely patent and gastroduodenal mucosa were normal on the gross endoscopic assessment (Figure 1C). Biopsy mucosa sampling of the anastomotic site (Figure 1D) revealed normal chronic fibrosis. On the last contact, at the seventh month PO, the owner informed that the patient was stable, with normal food intake and no episodes of vomiting.

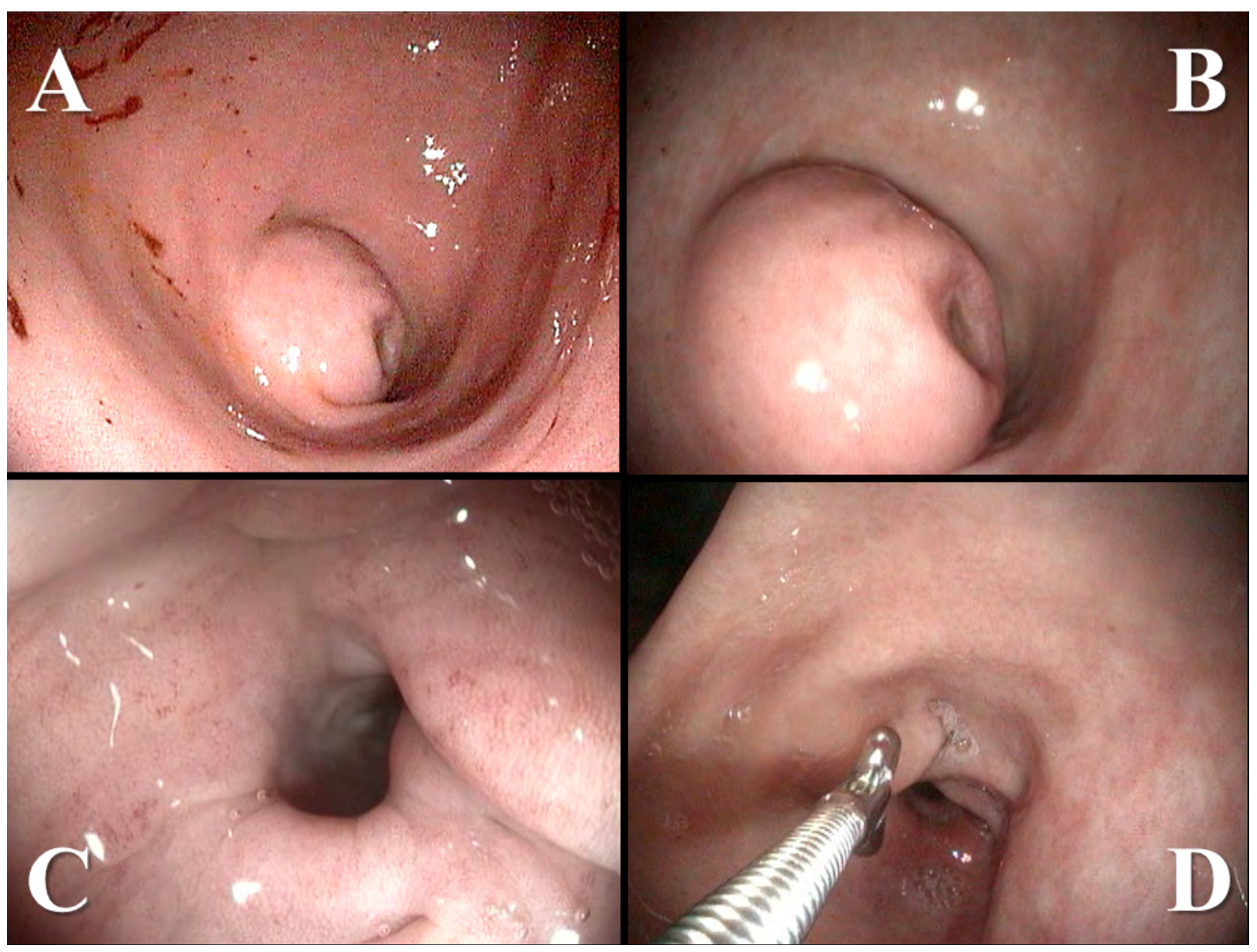

Figure 1. Pyloric leiomyoma in a Cocker Spainel bitch. A- Gastroscopic image showing a sessile, round-shaped, infiltrated and ulcerated mass at the antrum pyloric area. Several small bleeding ulcers are seen on the antrum pyloric mucosa. B-Close-up image of the mass, highlighting the presence of an ulcer. C- PO gastroscopic view of the gastroduodenal anastomosis, assuring complete patency. D- Endoscopic biopsy sampling of the anastomotic scar tissue to rule out local recurrence. 


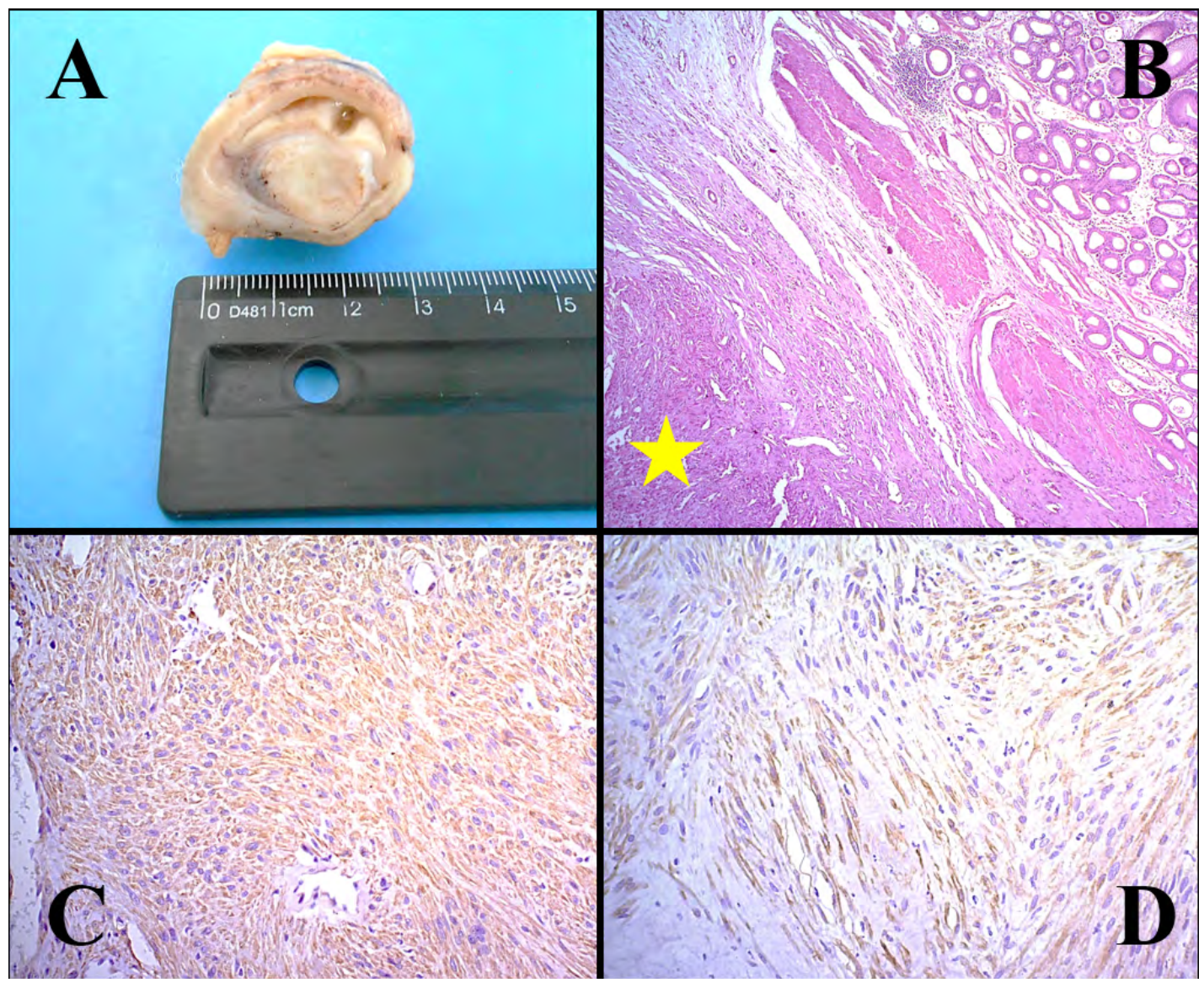

Figure 2. A- Gross aspect of the mass, presenting approximately $1.7 \mathrm{~cm}$ in diameter. The mass was encapsulated, presenting white-pale brown colour, soft/firm consistency and did not infiltrate the gastric mucosa. B- Histopathological image showing mature smooth muscle cells (star) slightly below the gastric muscular layer, which is limited and arranged in solid pattern [H\&E, 50x]. C \& D- Immunohistochemistry image of the mass, presenting immunostaining for actin (C) and desmin (D), confirming smooth muscle origin of the mass [IHC, polymer method with horseradish peroxidase (HRP), 40x].

\section{DISCUSSION}

Although uncommon in dogs, gastric neoplasms present high risk of severe chronic obstruction $[16,18]$. Adenocarcinoma is the most common gastric cancer in the canine specie, while lymphoma is the most frequent in cats. Other gastric neoplasms include leiomyoma, leiomyosarcoma, mast cells tumor, plasmacytoma, fibrosarcoma and gastrointestinal stromal tumor $[6,19]$.

Endoscopic examination is crucial on surgery decision making [1]. In this case report, endoscopy was important for both establishing surgical strategy and diagnosing gastric ulcer and lymphoplasmacytic inflammation. Moreover, biopsy sampling and endoscopic gross examination leaded to optimal approach. Multiple biopsy sampling is mandatory to diagnose gastric neoplasms [7]. However, it was not possible to confirm leiomyoma in this case. Despite several samples were taken from the same site, poor tissue quality resulted in inadequate histologic examination. Thus, complete surgical resection was necessary for both treating and investigating the primary cause $[4,11,14]$.

Early diagnosis of gastric tumor is optimal for accurate surgical intervention, and thus, for reaching better prognosis. In case of gastric polyps or small mucosa neoplasms, endoscopic resection may be accomplished [17]. However, endoscopic approach is not recommended for total resection of gastric smooth muscle layer, due to risk of complete perforation. For masses greater than two centimeters complete resection by conventional or laparoscopic approach should be considered $[11,13,22]$. In this patient, it was not possible to assure the depth of the mass. However, free movement of the gastric mucosa during biopsy sampling was an evidence of smooth muscle involvement. There was no specific endoscopic instruments for resection were available. Moreover, laparoscopic approach would be both time consuming and cost 
prohibitive in this case. Thus, we opted to perform the conventional Billroth I procedure.

In this patient, there was no involvement of biliary or pancreatic tracts. Thus, Billroth I procedure was suitable for pylorectomy and gastroduodenal anastomosis [16]. Wide-margin resection is essential. If integrity of biliary or pancreatic tract cannot be warranted, it requires gastrojejunostomy (Billroth II procedure) associated to biliary diversion techniques (colecystoduodenostomy or colecystojejunostomy). The need for those procedures impairs dramatically prognosis $[15,20]$. In this case, it was possible to resect affected area with free margins greater than two centimeters, according to principles of surgical oncology [4].

Proper anastomosis technique is an important issue on gastroduodenostomy. Monofilament absorbable sutures ranging from 2-0 to 4-0 USP are suitable. Chromic catgut should not be used as proteolysis is increased in the gastric environment [4]. Likewise, polydioxanone is unstable under acid environment and rapidly loses strength [15]. Thus, monofilament polyglecaprone 25 suture was used in this case. Polyglecaprone 25 is known as a gastric $\mathrm{pH}$-resistant thread, maintaining its properties and tension bearing for longer period [15].

Prognosis following Billroth I procedure in dogs is strongly affected by malignancy and postoperative weight loss, hypoalbuminemia and/or anemia. In those cases, survival time lower than 30 days is expected [6]. Despite progressive weight loss and anaemia were reported preoperatively, the benign nature of the gastric neoplasm leaded to good prognosis following surgery in this case. Gastric surgery-related complications include vomiting, anorexia, haemorrhage, anastomosis site ulcerations, septic peritonitis due to dehiscence and leakage, stenosis and gastric outflow obstruction, damage to the pancreatic and biliary tract, and metastasis due to malignancy $[6,19]$. If pancreatic duct is damaged, exogenous supplementation with enzymes should be provided postoperatively $[14,15]$.

Surgery is potentially curative in benign gastric neoplasms, except for lymphoma [9,15]. Pyloric tumors require wide margins of resection. Mesenteric and gas- tric lymph node should be assessed to rule out metastasis $[10,16]$. In the patient reported, there was no evidence of lymph nodes reaction, which were not sampled.

Microscopic low cellularity proliferation, tissue and cell type indicated benign smooth muscle neoplasm [1]. IHC was positive for actin and desmin, which are widely distributed in muscular layers. Moreover, tissue did not stain for CD 34 and C-Kit, which would suggest gastrointestinal stromal tumor $[2,8]$.

Complete resection with safe margins was confirmed histologically [15]. Incomplete resection could cause recurrence at the anastomosis site [16]. Additionally, we assured definitive resolution following repeated complementary exams and new gastroduodenoscopy. There was no stenosis or evidence of local recurrence and the patient was discharged.

In conclusion, pylorectomy/gastroduodenostomy was curative. Patients bearing pyloric obstructive leiomyoma present good prognosis following complete resection. Upper digestive endoscopy is essential for diagnosis and decision making on treatment of gastric outflow obstruction due to pyloric neoplasm. Histopathological and IHC diagnosis is crucial for establishing tumor type and assuring safe oncologic margins of resection and good prognosis.

\section{MANUFACTURERS}

${ }^{1}$ Roche Diagnóstica. São Paulo, SP, Brazil.

${ }^{2}$ Ethicon/Johnson \& Johnson do Brasil Ltda. São Paulo, SP, Brazil.

${ }^{3}$ Eurofarma Laboratórios S.A. Ribeirão Preto, SP, Brazil.

${ }^{4}$ Blau Farmacêutica S.A. São Paulo, SP, Brazil.

${ }^{5}$ Chemitec Agro-Veterinária Ltda. São Paulo, SP, Brazil.

${ }^{6}$ Fresenius Kabi Brasil Ltda. Aquiraz, CE, Brazil.

${ }^{7}$ Instituto de Hypodermia e Farmácia Ltda. Ribeirão das Neves, MG, Brazil.

${ }^{8}$ Boehringer Ingelheim Espanã S.A. Sant Cugat Del Vallés, Spain.

${ }^{9}$ EMS S.A. Hortolândia, SP, Brazil.

${ }^{10}$ Hipolabor Farmacêutica Ltda. Sabará, MG, Brazil.

${ }^{11}$ Easytech Life Sciences Ltda. Ribeirão Preto, SP, Brazil.

${ }^{12}$ Sinapse Biotecnologia Ltda. São Paulo, SP, Brazil.

Declaration of interest. The authors are responsible for the content of this article and declare no conflict of interest.

\section{REFERENCES}

1 Acker S., Dishop M., Kobak G., Vue P. \& Somme S. 2014. Laparoscopic-assisted endoscopic resection of a gastric leiomyoma. European Journal of Pediatric Surgery Reports. 2(1): 3-6.

2 Barra M.B. 2006. O uso da imunohistoquímica no diagnóstico: indicações e limitações. Revista da AMRIGS. 50(2): 173-184. 
3 Cooper B.J. \& Valentine B.A. 2002. Tumors of muscle. In: Meuten D.J. (Ed). Tumors in domestic animals. 4th edn. Ames: Iowa State Press, pp.319-364.

4 Cornell K. 2012. Stomach. In: Tobias K.M. \& Johnston S.A. (Eds). Veterinary surgery - small animal. Saint Louis: Elsevier, pp.1484-1512.

5 Day M.J. \& Bilzer T. 2008. Histopathological standards for the diagnosis of gastrointestinal inflammation in endoscopic biopsy samples from the dog and cat: a report from the World Small Animal Veterinary Association Gastrointestinal Standardization Group. Journal of Comparative Pathology. 138: 1-43.

6 Eisele J., Mcclaran J.K., Runge J.J., Holt D.E., Culp W.T., Liu S., Long F. \& Bergman P.J. 2010. Evaluation of risk factors for morbidity and mortality after pylorectomy and gastroduodenostomy in dogs. Veterinary Surgery. 39(2): 261-267.

7 Foale R.D. \& Demetriou J. 2011. Oncologia em pequenos animais. Rio de Janeiro: Mosby Elsevier, 224p.

8 Frost D., Lasota J. \& Miettinen M. 2003. Gastrointestinal stromal tumors and leiomyomas in the dog: a histopahologic, immunohistochemical, and molelur genect study of 50 cases. Veterinary Pathology. 40: 42-54.

9 Hall J.A. 2004. Doenças do estômago. In: Ettinger S.J. \& Feldman E.C. (Eds). Tratado de medicina interna veterinária: doenças do cão e do gato. 5.ed. São Paulo: Guanabara Koogan, pp.1218-1242.

10 Hu X., Tian D., Cao L. \& Yi Y. 2009. Progression and prognosis of gastric stump cancer. Journal of surgical oncology. 100(6): 472-476.

11 Huang L., Cui J., Wu C., Zhang B., Jiang L., Xian X., Lin S., Xu N., Cao X. \& Wang Z. 2014. Endoscopic fullthickness resection and laparoscopic surgery for treatment of gastric stromal tumors. World Journal of Gastroenterology. 20(25): 8253-8259.

12 Jones T.C., Hunt R.D. \& King N.W. 2000. Sistema digestivo. In: Jones T.C., Hunt R.D. \& King N.W. (Eds). Patologia veterinária. 6.ed. Barueri: Manole, pp.1087-1088.

13 Kosmidis C., Efthimiadis C., Anthimidis G., Vasileiadou K., Stavrakis T., Ioannidou G. \& Basdanis G. 2013. Endoscopically assisted laparoscopic local resection of gastric tumor. BMC Research notes. 6: 410-414.

14 Matthiesen D.T. 1998. Obstrução crônica e esvaziamento gástrico. In: Slatter D. (Ed). Manual de cirurgia de pequenos animais. 2.ed. São Paulo: Manole, pp.682-690.

15 Radlinsky M.G. 2014. Cirurgia do sistema digestório. In: Fossum T.W. (Ed). Cirurgia de pequenos animais. 4.ed. Rio de Janeiro: Elsevier, pp.461-497.

16 Rasmussen L. 2007. Estômago. In: Slatter D. (Ed). Manual de cirurgia de pequenos animais. 3.ed. Barueri: Manole, pp.592-641.

17 Stanton M.L.E. 1996. Ulceração e neoplasia gástrica. In: Bojrab M.J. (Ed). Mecanismos da moléstia na cirurgia dos pequenos animais. 2ed. São Paulo: Manole, pp.275- 277.

18 Sturgess C.P. 2001. Doenças do trato alimentar. In: Dunn J.K. (Ed). Tratado de medicina de pequenos animais. São Paulo: Roca, pp.367-409.

19 Swann H.M. \& Holt D.E. 2002. Canine gastric adenocarcinoma and leyomyosarcoma: a retrospective study of 21 cases (1986-1999) and literature review. Journal of the American Animal Hospital Association. 38(2): 157-164.

20 Walter M.C., Matthiesen D.T. \& Stone E.A. 1985. Pylorectomy and gastroduodenostomy in the dog: technique and clinical results in 28 cases. Journal of the American Veterinary Medical Association. 187: 909-914.

21 Willard M.D. 2010. Distúrbios do sistema digestório. In: Nelson R.W. \& Couto C.G. (Eds). Medicina Interna de Pequenos Animais. 4.ed. Rio de Janeiro: Mosby Elsevier, pp.351-484.

22 Zhang B., Huang L., Wu C., Cui J., Jiang L. \& Zheng H. 2013. Endoscopic full-thickness resection of gastric stromal arising from the muscularis propria. Chinese Medical Journal. 126(13): 2435-2439. 